\title{
Contribuições do Planejamento Participativo Regionalizado (PPR) para a ampliação da cidadania e promoção da saúde
}

\author{
Contributions of Participatory Regionalized Planning (PPR) for the \\ expansion of citizenship and health promotion
}

Maria de Fátima Abreu1, Elza Machado de Melo², Andréa Maria Silveira ${ }^{\mathbf{3}}$

DOI: $10.1590 / 0103-110420185408$

RESUMO O objetivo do estudo foi aferir se o Planejamento Participativo Regionalizado (PPR), ocorrido em Belo Horizonte (MG), entre 2011 e 2012, amplia a cidadania, qualifica as políticas públicas e pode afetar positivamente os determinantes da saúde. Foram realizadas análise documental e entrevistas. Verificou-se que o PPR foi realizado de forma transparente e representativa. A sua metodologia foi bem avaliada, principalmente pelas suas características lúdicas. O PPR propiciou integração de atores envolvidos em políticas públicas distintas e trouxe a dimensão do planejamento de médio e longo prazo. A sua experiência traz inspirações técnicas e metodológicas que podem possibilitar a ampliação da cidadania.

PALAVRAS-CHAVE Planejamento participativo. Promoção da saúde. Democracia.

1Universidade Federal de Minas Gerais (UFMG)

- Belo Horizonte (MG), Brasil

Orcid: https://orcid. org/0000-0001-7201-

4186

fabreu03@gmail.com

2 Universidade Federal de Minas Gerais (UFMG)

- Belo Horizonte (MG),

Brasil

Orcid: https://orcid.

org/0000-0002-3577-

0721

elzammelo@hotmail.com

${ }^{3}$ Universidade Federal de

Minas Gerais (UFMG)

- Belo Horizonte (MG),

Brasil

Orcid: https://orcid.

org/0000-0002-1180-

3875

silveira@medicina.ufmg.br
ABSTRACT The objective of the study was to assess whether Participatory Regionalized Planning (PPR), held in Belo Horizonte (MG), between 2011 and 2012, broadens citizenship, qualifies public policies and can positively affect health determinants. Documental analysis and interviews were carried out. It was verified that the PPR was performed in a transparent and representative manner. Its methodology was well evaluated, mainly for its playful features. The PPR allowed the integration of actors involved in different public policies and brought the dimension of medium and long term planning. Its experience brings technical and methodological inspiration that can make possible the expansion of citizenship.

KEYWORDS Participative planning. Health promotio. Democracy. 


\section{Introdução}

A Política Nacional de Promoção da Saúde reconhece a participação social como um dos fatores de promoção da saúde ${ }^{\mathbf{1}}$ acolhe como importante o engajamento social no desenvolvimento, na implementação, no monitoramento e na avaliação das políticas de saúde. Essa produção não é de responsabilidade apenas do setor saúde, visto que as iniquidades em saúde têm como causa as condições em que as pessoas nascem, crescem, vivem, trabalham e envelhecem, as experiências individuais de educação, emprego e trabalho, habitação e meio ambiente e de acesso a serviços de prevenção e tratamento de doenças. As intervenções sobre esses determinantes são essenciais para sociedades produtivas, inclusivas e saudáveis ${ }^{2}$.

No Brasil atual, a participação social representa um elemento estruturante nas políticas sociais. Discuti-la é importante para o entendimento do processo de institucionalização e execução das políticas públicas, enquanto estratégia para a redução das desigualdades. Aqui, ressalta-se a emergência no País de outras formas de participação na gestão do social e na prestação de serviço para além dos conselhos, como fruto do fortalecimento de um movimento que tem suas origens na década de $1980^{3}$.

Nos anos 1990, emergiram novos e variados mecanismos de participação e inclusão de atores sociais na produção de políticas públicas, mas os espaços institucionalizados de participação se voltaram mais para o controle social da gestão pública do que para a construção de visões compartilhadas de futuro. Os conselhos e outros mecanismos de participação social acumularam pouca experiência em processos de concertação, negociação e direcionamento estratégico das políticas governamentais ${ }^{4}$. Na última década, há uma tentativa do planejamento setorial de romper com a precedência e a primazia do orçamento sobre o planejamento ${ }^{5}$.

Com a aprovação, em 2001, do Estatuto da Cidade, foi regulamentado o capítulo da
Constituição sobre a política urbana, com ênfase na inclusão territorial e na diminuição das desigualdades socioespaciais. Foram promovidos processos participativos na elaboração e na revisão dos Planos Diretores, mas esses processos não resultaram, necessariamente, em Planos que expressam a construção de um pacto social para o desenvolvimento urbano, com manutenção da cisão entre a visão técnica da cidade e a visão comunitária ${ }^{6}$. Belo Horizonte, inaugurada em 1897, foi uma das primeiras cidades brasileiras planejadas, tendo sido projetada para ser a capital de Minas Gerais7. Concebida para 200 mil habitantes, em pouco mais de um século, tornou-se uma das principais capitais do País, com 2,38 milhões de habitantes ${ }^{8}$.

Em 1993, o município iniciou o processo de democratização, com a implantação do Orçamento Participativo (OP) e a criação dos vários conselhos de políticas públicas. Entre 1993 e 1996, ocorreu a aprovação da Lei Orgânica do Município e do Plano Diretor da cidade.

Entretanto, a cidade foi considerada, em 2010, uma das cidades mais desiguais do mundo 9 . O seu histórico de participação social, principalmente pelo OP e pela atuação dos conselhos de políticas públicas e de planejamento urbano, a partir da década de 1990, não foi, portanto, suficiente para reverter a sua desigualdade social.

O OP Regional teve sua primeira edição em 1993, e, durante os cinco primeiros anos, o processo aconteceu anualmente. A partir de 1999, passou a ser realizado de dois em dois anos. $\mathrm{O}$ segundo tipo, o OP da Habitação (OPH), foi iniciado em 1996, para construção de unidades habitacionais para famílias sem moradia ${ }^{10}$. Já o terceiro tipo, o OP Digital, aconteceu em 2006, 2008, 2011 e 2013, via internet e aberto a todos os eleitores, e busca viabilizar obras de maior abrangência e a incorporação de novos segmentos da população, principalmente a classe média e a juventude.

Em pouco mais de 20 anos, o OP trouxe conquistas consideráveis, principalmente para as comunidades mais vulneráveis, com 
a requalificação dos espaços e de acessibilidade. Essas intervenções demonstram uma inversão de prioridades dos investimentos públicos em espaços urbanos de maior risco e vulnerabilidade social.

Além do OP, há, em Belo Horizonte, 24 conselhos municipais de políticas públicas, com diferentes graus de maturação, diversidade de entendimentos, pluralidade de representação e distintas dinâmicas de funcionamento, além de diferenças quanto ao caráter deliberativo e/ou consultivo e à infraestrutura. Existem, ainda, centenas de outras instâncias participativas ou temáticas, como comissões, comitês, conferências, fóruns e uma grande variedade de espaços de participação social, além de conferências temáticas e audiências públicas.

Contudo, não existem mecanismos participativos que promovam discussões intersetoriais ou transversais às diversas políticas públicas, o que culmina na perda da perspectiva mais global na qual essas políticas se inserem. A ausência desses mecanismos poderia ser minimizada pela maior articulação entre conselhos, conferências, ouvidorias, audiências e consultas públicas, entretanto, isso não ocorre ${ }^{4}$.

Em fevereiro de 2011, a prefeitura se propôs a fortalecer a gestão participativa em Belo Horizonte, ao criar a Secretaria Municipal Adjunta de Gestão Compartilhada (SMAGC), vinculada à Secretaria Municipal de Governo, com o desafio de articular, dar unidade e potencializar a participação democrática no município. Foi definida, como prioridade para ação da Secretaria, a estruturação de um novo processo de diálogo do governo municipal com a sociedade, por demanda do prefeito (Márcio Lacerda), que queria ouvir diretamente as propostas das comunidades para o aprimoramento das políticas públicas em todas as regiões da cidade. Assim, entre 2011 e 2012, foi empreendido o Planejamento Participativo Regionalizado (PPR), pelo Decreto Municipal ${ }^{\circ}{ }^{0} 4.724$, em dezembro de 2011, envolvendo grande diversidade de atores sociais, com cerca de 9 mil participações, que geraram 2.500 proposições para os 40 territórios do município ${ }^{11}$.

O PPR buscava direcionar os recursos públicos de forma mais alinhada às necessidades e demandas da população, estabelecer metas referentes a aspectos subjetivos e qualitativos do processo e criar uma cultura de planejamento de médio e longo prazo, com a formação de cidadãos mais envolvidos na gestão municipal. Buscava, ainda, identificar propostas mais adequadas para o desenvolvimento de cada região da cidade com a discussão de ações nos diversos setores - habitação, saúde, educação, desenvolvimento social, transporte e trânsito, trabalho e renda, lazer, segurança, cultura, meio ambiente - e se contrapor à compartimentalização temática dos processos participativos, abrigando todas as questões trazidas pelos participantes. Visando a identificar em que medida o PPR avança com relação às experiências anteriores da democracia participativa, esta pesquisa objetivou descrever o desenho e o processo dessa experiência de PPR de Belo Horizonte.

\section{Metodologia}

Trata-se de estudo de natureza qualitativa, baseado na análise de documentos, entre os quais se destacam registros realizados durante o desenvolvimento do PPR, Fichas de Avaliação dos Eventos preenchidas pelos participantes, relatos de reuniões de equipes (detalhamento do planejamento, definição das dinâmicas dos encontros públicos e dos instrumentos usados para articulação, mobilização, comunicação e condução dos eventos, monitoramento e avaliação do PPR). Foram, ainda, realizadas de forma complementar e visando a um maior aprofundamento quanto à percepção dos participantes, entrevistas com informantes-chave (lideranças comunitárias, técnicos e gestores municipais), um ano após a conclusão do processo, utilizando roteiro que continha perguntas sobre avaliação dos 
participantes acerca de aspectos principais do PPR. Foram utilizados os registros de duas oficinas internas de planejamento do PPR realizadas pela equipe da Gerência de Mobilização Social e 2.671 fichas de avaliação de 49 encontros realizados, entre 2011 e 2012. Lançou-se mão, ainda, de dois boletins informativos, gravações em áudio e vídeos, clippings da imprensa, folder, panfletos, cartazes, convites, apresentações visuais e fotografias.

O tratamento analítico desse material teve como marco teórico referencial a concepção de consenso de Habermas e dos neo-habermasianos. A partir disso, as instâncias de participação da população na discussão das políticas públicas, como conselhos, fóruns, conferências etc., foram consideradas como espaço de construção do consenso, no qual interesses distintos convergem, por meio de acordos, para o interesse de todos, segundo categorias propostas por Pires ${ }^{\mathbf{4}}$ e Smith ${ }^{\mathbf{1 2}}$ e De Ferrari et al. ${ }^{13}$, e com as quais foi feita a análise do PPR: i) transparência sobre intenções, objetivos, alcances, processos e resultados da participação e divulgação ampla para o público em geral; ii) representatividade e inclusão: interesses relevantes representados e possibilidade de todos os participantes expressarem suas opiniões e de serem ouvidos; iii) institucionalidade: ambientes, regras e configuração institucional que favoreçam a negociação e a formação de pactos e consensos; iv) equipe profissional qualificada e isenta: capacidade técnica, isenção e neutralidade dos profissionais que conduzem o processo; v) empoderamento dos participantes: autonomia e capacidade de fazer valerem as decisões; vi) compromisso da autoridade e apoio institucional: autoridade convencida e comprometida com a abertura de sua gestão à intervenção cidadã; vii) resultados: que permitam assegurar efeitos positivos, que atendam às expectativas dos participantes. Esta pesquisa foi aprovada pelo Comitê de Ética da Universidade Federal de Minas Gerais (UFMG), CAAE 02335212200005149 , e contou com a anuência da Prefeitura de Belo Horizonte.

\section{Resultados e discussão}

\section{O processo do PPR}

O município de Belo Horizonte é subdividido em 9 regionais administrativas. Os aproximadamente 2,5 milhões de habitantes estão distribuídos em cerca de 500 bairros e vilas. Em 2010, foi proposta uma nova organização do município em 40 territórios de Gestão Compartilhada, constituídos pelo agrupamento de vários bairros semelhantes em termos de infraestrutura e aspectos socioeconômicos. O PPR teve como base territorial essa nova organização"1, que constou de articulação interna da prefeitura, reuniões preparatórias e ciclos progressivos de oficinas públicas, e foi estruturado, em sua Primeira Etapa, em cinco ciclos de oficinas públicas. O 'Ciclo A' Conhecendo e debatendo a Metodologia -, de âmbito regional, focou a sensibilização para a importância do planejamento participativo e a apresentação da proposta do PPR em cada Regional, com livre expressão dos participantes. A proposta era tratada de forma lúdica com a exibição de um vídeo e a apresentação de esquete por um grupo de teatro. Ao final, era apresentado o Ciclo B e eram fornecidos convites para serem distribuídos nos bairros. O 'Ciclo B' - Formulando propostas para os Territórios - tratou da criação dos Grupos de Trabalho Territorial (GTTs) e foi destinado à escuta das propostas de médio e longo prazo para cada um dos 40 territórios. Em grupos, os representantes discutiram e formularam as propostas para a melhoria e o desenvolvimento do seu território. Em cada território, eram formados 2 subgrupos, para os eixos Social/Cultural e Ambiental/Econômico. O eixo de Gestão Compartilhada era discutido nos dois grupos. Ao término das oficinas, eram definidos de 10 a 15 participantes de cada território para, junto com técnicos da Gerência de Mobilização Social, sistematizar as propostas a serem levadas ao Ciclo C. Esses representantes compuseram o Grupo de 
Trabalho Territorial (GTT), para cada um dos 40 territórios. No 'Ciclo C' - Diálogos com o Prefeito -, as oficinas de âmbito regional promoviam o diálogo entre os representantes dos territórios e o prefeito municipal. A dinâmica dessas oficinas dava a palavra, em primeiro lugar, à comunidade, e, em seguida, ao prefeito, que antecipava encaminhamentos e/ou informações sobre obras, projetos e programas em andamento. Após esse Ciclo, foi realizada a 'Análise técnica das propostas - criação do Grupo Técnico de Avaliação das propostas (GTA)'. O prefeito convocou os dirigentes de órgãos, secretários e dirigentes de Regionais para indicarem técnicos para analisarem as mais de 2.500 propostas do PPR sobre diferentes temas. O GTA envolveu representantes de 27 áreas temáticas da prefeitura e das 9 Administrações Regionais para esse trabalho de análise. O ‘Ciclo D' - Entrega dos 'Cadernos de Análise das Propostas' -, também de âmbito regional, teve como objetivo o retorno à comunidade dos encaminhamentos dados pela prefeitura às propostas apresentadas. Um secretário de área temática da prefeitura também fazia uma exposição da política municipal da qual ele era titular. O tema era definido segundo as propostas mais frequentes naquela Regional. No 'Ciclo E' - Fórum da Cidade -, de âmbito municipal, deveriam ser apresentados os principais resultados referentes às proposições populares, mas o Ciclo não foi realizado devido ao acúmulo de eventos participativos nesse período (do OP e dos Planos Diretores Regionais) e pela proximidade com as eleições municipais. Assim, ao final dos encontros públicos do Ciclo D, foi proposta a continuidade do PPR para aprofundamento das discussões sobre as propostas para cada território. O PPR foi estruturado, portanto, como um processo permanente de planejamento, que deveria ser contínuo, após essa Primeira Etapa de formulação e análise das propostas, para revisão e acompanhamento sistemático da execução das propostas. Entretanto, o processo não teve continuidade.

\section{A percepção dos participantes}

No que diz respeito à categoria 'Transparência', várias ações foram empreendidas. As Secretarias Regionais foram as que mais se envolveram, utilizando peças de comunicação como folders, informativos, panfletos, cartazes e convites. Os dois boletins informativos produzidos ao longo do trabalho, postados pelo correio e distribuídos nas oficinas, buscavam difundir o projeto e informar sobre o andamento das atividades, além da divulgação em jornais locais e blogs. A TV Conecta da PBH produziu vídeos divulgados no Portal da $\mathrm{PBH}$.

Nas reuniões de avaliação do processo pela equipe da Gerência de Mobilização Social, as oficinas do Ciclo A foram percebidas como uma 'catarse coletiva'. O clima era permeado por dúvidas e desconfiança sobre as reais intenções do PPR e potenciais ameaças à continuidade do OP, fonte de muitas conquistas para as comunidades mais pobres.

Irei continuar observando as propostas, participando dos ciclos que vão acontecer, para amadurecer de fato a minha decisão com relação ao PPR. (Liderança Comunitária).

Houve acusações de oportunismo: "O prefeito vai usá-las (as obras) na sua plataforma de governo para se reeleger" (Membro da Comunidade).

Houve, também, muitas declarações de expectativas positivas: "Eu gostaria que este projeto venha contribuir de fato para a evolução de BH, especificamente, o Barreiro" (Membro da Comunidade).

Com relação à compreensão da proposta, as observações foram variadas, identificando-se posicionamentos antagônicos entre participantes de uma mesma oficina:

'Eu achei boa porque esclareceu dúvidas que a gente tinha'; 'Não entendi nada'; 'Muito ruim, que as pessoas não falavam nada com nada'; 'Me parece que a gestão compartilhada tem tudo a ver com o orçamento participativo'. (manifestações de Membros da Comunidade). 
Quanto à categoria 'Representatividade e Inclusão', foi constituído um Banco de Dados de lideranças, classificado por regionais e territórios, com mais de 11.000 participantes, que receberam convites para as oficinas e reuniões. A representação mais expressiva foi de associações populares, destacando-se lideranças comunitárias do OP, membros de conselhos de políticas públicas e de comissões regionais/locais da cidade e, em escala menor, representantes de associações de moradores, de Organizações Não Governamentais (ONGs), de sindicatos e de comunidades religiosas. Registre-se a difícil mobilização da classe média, do setor produtivo e de jovens, presentes em pequena proporção. As fichas de avaliação das oficinas e as reuniões de avaliação apontaram que, para os participantes, deveria ter sido feita uma divulgação maior, para ampliar o número de pessoas, e o processo deveria ter sido mais aberto.

Calsing ${ }^{\mathbf{1 4}}$ considera que todo planejamento tem traços impositivos, porque depende de coordenação e condução. Pedro Demo ${ }^{15}$ reitera que o planejamento é um fenômeno que tende a ser dominador, mas observa que não se pode menosprezar a necessidade de coordenação. Para ele "não há coordenação satisfatória sem participação das bases, e não há participação condizente das bases sem o elemento coordenador"15(15). No caso do PPR, porém, a definição do desenho institucional e da metodologia (institucionalidade) foi de inteira responsabilidade da equipe coordenadora, composta por técnicos da $\mathrm{PBH}$, que se preocupou em criar ambiente acolhedor e propiciar uma escuta empática e afetiva a todos os participantes. O diferencial no PPR foi essa dimensão afetiva e acolhedora, desde a recepção das pessoas com um lanche coletivo, a animação lúdica pela equipe de arte-mobilização, a condução também lúdica do mestre de cerimônias e a apresentação dos esquetes teatrais tratando de temas relacionados aos eventos. A metodologia foi referenciada de forma positiva pelos participantes da avaliação do PPR, em 2013. Considerou-se que o processo humanizou a política, tendo sido destacado o caráter informal dos eventos: "Um fator positivo foi a maneira que escolheram para levar a informação via teatro, a abertura. $O$ que poderia ter sido mais usado" (Técnico da $\mathrm{PBH})$. Nas Fichas de Avaliação, também houve destaque para o teatro: "O teatro ilustrou bem o assunto, levantou o ânimo. O encontro foi, no geral, esclarecedor" (Membro da Comunidade). Lideranças e gerentes de OP consideraram positivo que a metodologia possibilitou discutir todas as questões simultaneamente. " $\mathrm{Um}$ aspecto positivo foi a visão do todo da prefeitura" (Técnico da PBH).

O Ciclo B foi o único ciclo em que os encontros aconteceram por território, e os participantes foram subdivididos em grupos. Esse formato teve uma boa receptividade, pela maior oportunidade de todos se manifestarem: "O formato utilizado para esta oficina foi interessante e mais proveitoso" (Membro da Comunidade). As fichas também continham observações sobre as limitações das propostas formuladas, alertando para a necessidade de maior informação e embasamento técnico:

\section{Existem propostas sem embasamento técnico que} justifique as implantações. (Técnico da PBH).

Ser mais objetivo. A prefeitura trazer as propostas que ela tem para a região. (Liderança Comunitária).

Na avaliação do PPR no Ciclo D, em uma das Regionais, uma liderança destacou como aspecto positivo a apresentação das propostas pelos GTTs para o prefeito, ressaltando a importância da 'inversão de metodologia' em relação a outros processos participativos na cidade:

[...] quando tem evento com prefeito, monta-se palanque, prefeito e outras autoridades falam, falam e falam. E o povo só escuta. Depois, todos da mesa saem antes do povo falar. Essa inversão na metodologia foi muito importante. O povo falou primeiro, ele ouviu. (Liderança Comunitária). 
Pôde-se verificar que $83 \%$ dos participantes avaliaram como Boas ou Muito Boas as oficinas nas Regionais nos 3 primeiros ciclos e que apenas $5 \%$ consideraram que as oficinas deixaram a desejar. Cabe observar que a média da avaliação positiva foi crescente: no Ciclo A, foi de $79 \%$, passando para $84 \%$ no Ciclo B, e chegando a $88 \%$ no Ciclo C.

No que diz respeito à categoria 'Equipe Profissional Qualificada', a equipe da Gerência de Relacionamento e Mobilização Social da Secretaria de Gestão Compartilhada foi responsável pelo conteúdo, metodologia, dinâmica, moderação e relatoria das discussões em grupo, da arte-mobilização e do monitoramento das ações. Os técnicos tinham experiência em mobilização social e contavam com consultoria especializada, propiciando escuta qualificada das questões trazidas pela comunidade. Essa receptividade foi reconhecida pelos participantes durante o processo:

Foi uma metodologia exemplar, que funcionou. [...] Tem muito a ver com o corpo técnico. Não houve indução para que as pessoas falassem o que se queria ouvir. O pessoal percebeu isso. (Liderança Comunitária).

A categoria 'Empoderamento' dos participantes implica a autonomia e a capacidade de fazer valerem as decisões e de institucionalizar a vontade dos participantes; a possibilidade de desafiar práticas estabelecidas e a capacidade de gerar 'melhores cidadãos'. Uma liderança, ao fazer avaliação do PPR na oficina do Ciclo D, destacou o impacto do processo:

[...] eu acho que cada um aqui vai concordar comigo. É que o planejamento, ele faz com que a gente seja uma liderança mais completa, vocês não acham, não? (Liderança Comunitária).

Nas reuniões e entrevistas de avaliação do PPR, em 2013, lideranças, técnicos e gestores avaliaram que houve problemas na análise das propostas pelos técnicos da prefeitura (GTA). Segundo uma secretária, "Não houve avaliação sobre a pertinência de considerar uma proposta nova" (Técnico da $\mathrm{PBH}$ ), e as propostas "foram se enquadrando naquilo que já estava sendo feito" (Técnico da PBH).

Além das reuniões sistemáticas com a equipe da Secretaria de Gestão Compartilhada, muitos técnicos do GTA se dispuseram a participar dos encontros noturnos com representantes dos GTTs de cada Regional, para afinar a metodologia que estava sendo usada para análise das propostas. O trabalho de análise das mais de 2.500 propostas demandou muito esforço das equipes, mas, ainda assim, resultou em fragilidades, inclusive por não haver uma orientação política sobre até onde poderia haver comprometimento com as informações repassadas.

Na categoria 'Compromisso da autoridade e Apoio institucional', verificou-se que, até 2011, os processos participativos em Belo Horizonte aconteciam de forma descentralizada e desarticulada. A criação da Secretaria Municipal Adjunta de Gestão Compartilhada, para potencializar a participação social, vinculada à Secretaria Municipal de Governo, órgão de coordenação política da gestão municipal diretamente ligado ao prefeito, foi uma sinalização de fortalecimento político da democracia participativa na cidade.

A partir da convocação do prefeito, as secretarias regionais demonstraram boa receptividade ao processo e deram apoio na mobilização e na realização das atividades do PPR. O prefeito disponibilizou sua agenda às oficinas do Ciclo $\mathrm{C}$ nas Regionais, quando ouviu a síntese das cerca de 2.500 propostas formuladas para toda a cidade.

Praticamente todos os participantes das reuniões de avaliação do PPR, em 2013, criticaram a falta de continuidade do processo. Um Secretário avaliou: "Lamentável foi esse hiato, de não ter tido claramente continuidade" (Técnico da PBH). Outro técnico também comentou: "É preciso ter cuidado com um processo que leva as pessoas a darem opiniões que não serão implementadas" (Técnico da PBH). Alguns participantes levantaram a hipótese de que o PPR foi empreendido para aumentar o capital político do governante 
no período pré-eleitoral. Segundo eles, o processo serviu como insumo para o prefeito e para a campanha de reeleição. Conseguiu movimentar lideranças e obteve alguns respaldos para sua elaboração programática.

Na categoria 'Resultados', verificou-se, em entrevistas de avaliação do PPR, feitas em 2013, que as pessoas que participaram avaliaram positivamente. Embora tenha se iniciado com certa descrença e temor de que o PPR iria substituir o OP, o retorno da prefeitura com relação às propostas apresentadas demonstrou o comprometimento com o processo e o respeito à população, e por isso ganhou credibilidade.

Quanto ao cumprimento das metas previstas, os resultados ficaram acima da expectativa em termos de número de eventos, de participações, incorporação de novos segmentos, mapa de lideranças e propostas sistematizadas. Foram realizadas 76 oficinas durante os quatro ciclos, realizados encontros intermediários, como reuniões com os GTTs, com o GTA e oficinas com representantes desses dois grupos, antes do Ciclo D. Considerando as reuniões preparatórias, somam-se 127 reuniões durante o PPR e um total de 203 eventos. Em todo o processo do PPR, foram computadas mais de 9.000 participações.

Destacam-se, como instrumentos de legitimação do processo, a sistematização e a impressão dos 'Cadernos de Propostas' e os 'Cadernos de Análise das Propostas' do PPR. A expectativa dos participantes de ter acesso à sistematização das propostas foi evidenciada em observações das Fichas de Avaliação:

A possibilidade de as pessoas falarem e terem a opinião registrada, isso é bom. É importante que isso se transforme em um documento para todos. (Membro da Comunidade).

Da mesma forma, os participantes demandaram ter acesso à avaliação das propostas pela prefeitura: "Acolher todas as propostas por escrito e respondê-las, fazer funcionar a comunicação prefeitura-lideranças comunitárias” (Liderança Comunitária).
Boa parte das propostas referiu-se a ações já previstas nos programas e projetos municipais, demonstrando conhecimento e interesse da comunidade nesses programas. Entre elas, a ampliação de equipamentos públicos, como Unidades Municipais de Educação Infantil (Umeis), Unidades de Saúde, melhorias no atendimento dos serviços de saúde, na limpeza urbana, no transporte coletivo, na cultura e nos esportes: o PPR "permitiu ampliar diretrizes do OP Regional 2013/2014, que estavam praticamente engessadas" (Técnico da PBH). Isso já era previsto na concepção do PPR, a perspectiva de balizar outros processos de planejamento em curso, como o próprio OP, os Planos Diretores Regionais e os próximos Planos Plurianuais de Ação Governamental (PPAGs).

Com relação às expectativas dos participantes sobre os resultados do processo, várias observações das Fichas de Avaliação das oficinas demonstraram grande desejo de que as propostas fossem concretizadas. Devem-se destacar, também, os resultados organizativos do processo. Nas oficinas do Ciclo B, inscreveram-se 670 pessoas para comporem os GTTs, das quais, 370 participaram efetivamente como referências em planejamento participativo dos 40 territórios. Dessas, 96 foram relatoras no Ciclo C e foram protagonistas na avaliação do processo no Ciclo D.

A instituição do GTA, composto por técnicos da PBH de todas as áreas temáticas, também foi um resultado organizativo importante. A convocação de 27 órgãos setoriais da prefeitura, além das 9 secretarias regionais, e uma participação média de 30 pessoas nas reuniões promoveu o início de articulação intersetorial entre os órgãos municipais, buscando maior integração entre as políticas públicas no território.

Assim, efeitos positivos do PPR na estrutura interna da prefeitura também foram destacados. Técnicos do GTA constataram que várias secretarias trabalhavam com políticas que tinham interface, mas não conversavam. Como a continuidade do PPR não aconteceu, o GTA se dissolveu, e esse processo de integração intersetorial também foi interrompido. 
Quanto aos resultados pedagógicos, considera-se que as lideranças ficaram mais informadas, com maior percepção do todo e do aspecto territorial/regional. Isso foi destacado pelos gerentes de OP e por um Secretário Regional, nas reuniões de 2013:

A comunidade entendeu que não era só falar da sua rua, mas também do bairro e região em que moram [...]. O processo deu essa visão mais regional, municipal e fez com que deixassem de lado um pouco desse imediatismo. (Gestor $\mathrm{PBH}$ ).

\section{Discussão dos resultados}

Apesar da resistência dos participantes em ampliar o alcance das propostas para o médio e o longo prazo, bem como a sua abrangência espacial, foram formuladas questões mais abrangentes no espaço e no tempo, evidenciando o início da percepção de planejamento pretendida. Pode-se considerar que a distinção entre OP e PPR e a noção de planejamento foram mais incorporadas pelas lideranças que participaram mais ativamente do processo, no caso, a maioria dos GTTs.

A partir do Ciclo B, percebeu-se maior receptividade e um melhor entendimento da proposta, embora ainda houvesse desconfiança e certa incompreensão por parte de alguns participantes. Quanto ao caráter da inclusão, poderia se pensar que o fato de Belo Horizonte possuir uma tradição em OP seria uma condição importante para que houvesse maior equidade na participação. Entretanto, deve-se considerar que procedimentos visando à redução das assimetrias e desigualdades não são comuns nos $\mathrm{OPs}^{16}$, assim como nos Conselhos ${ }^{17}$, devido à complexidade das regras dos OP, não compreensíveis para todos, à falta de informação adequada e à necessidade de capacitação $^{\mathbf{1 8 , 1 9}}$. Ademais, estudos apontam que os cidadãos mais presentes nas instâncias participativas participam quase sempre em uma ou várias associações e frequentemente têm militância político-partidária, ou seja, "a inclusão política por meio da participação diz respeito aos cidadãos já incluídos no sistema representativo"18(342).

Cornely ${ }^{20(36)}$ avalia que:

[...] boa parte dos insucessos de experiências de desenvolvimento de comunidade se devem à falta de habilidade, à insuficiência ou à má composição da equipe técnica.

Considerando que uma boa equipe técnica deve ajudar a comunidade a mover-se eficazmente na direção que ela escolheu, destaca-se que a literatura brasileira sobre participação comunitária ${ }^{21-23}$, principalmente nos conselhos de saúde, chama atenção ao fato de as instâncias de participação serem criadas à imagem de gestores e profissionais, que convidam à participação e à adesão a comunidade, ainda que o dito modelo seja muitas vezes estranho à cultura dos diversos grupos sociais e dificulte a sua compreensão. Além disso, os segmentos técnicos, detentores de conhecimento, acabam por ter maior peso nas decisões e por impor uma linha técnica aos debates, o que culmina muitas vezes por excluir os não familiarizados com a linguagem científica.

Tais fatos colocam a população em posição de desvantagem nessas instâncias, a qual é agravada pela falta de disponibilidade de tempo, recursos para transporte e assessoria, ou seja, uma série de recursos geralmente disponíveis para a participação dos demais segmentos. Os depoimentos sugerem que nesta experiência de PPR a equipe técnica foi um dos fatores determinantes para que $o$ processo lograsse resultados importantes, ao buscar uma condução que procurava facilitar a participação da comunidade, dentro das limitações impostas por outros aspectos fora do controle da equipe.

Para Cornely ${ }^{\mathbf{2 0}}$, o planejamento participativo demanda ações de educação e trata-se de processo eminentemente pedagógico e de capacitação progressiva. Pedro Demo ${ }^{15}$ reforça essa percepção, afirmando que a força 
da educação está "na dimensão política, como incubadora da cidadania e cristalizadora das regras democráticas de jogo".

A concepção metodológica do PPR privilegiou os aspectos pedagógicos, políticos e organizativos da comunidade, aproximando-se, portanto, desses preceitos. Em alguns momentos, algumas lideranças se mostraram surpresas de poderem interferir na decisão de uso de recursos para além do que estava previsto no Orçamento Participativo. Em algumas oportunidades, os participantes questionaram sobre qual era a garantia de que as propostas formuladas no PPR seriam implementadas. A resposta era sempre de que não havia nenhuma garantia. Mas eles puderam perceber que, se no OP os participantes deliberam sobre uma pequena parcela do orçamento municipal, o PPR, embora não deliberativo, abriu a oportunidade para que as pessoas interferissem em todo o orçamento do município e entendessem que ainda poderiam ser buscadas fontes externas de recursos.

Outro aspecto importante na categoria 'Empoderamento dos participantes' foi a integração do saber popular e técnico. É provável que a comunidade cometa erros, na perspectiva do técnico. O técnico não é um elemento neutro e deve buscar instrumentalizar a comunidade a decidir melhor, como parte do processo educativo do planejamento participativo 20 .

$\mathrm{O}$ retorno à sociedade tem o potencial de proporcionar debate e reflexão, bem como agregar conhecimento ao cidadão. Assim, a entrega dos 'Cadernos de Propostas' ao Prefeito, no Ciclo C, e dos 'Cadernos de Análises das Propostas' aos participantes, no Ciclo D, foi um importante resultado do processo, embora a análise tenha sido considerada superficial e insuficiente para uma parte das propostas.

De fato, grande parte das propostas é de curto prazo, refletindo o fato de que as pessoas participam visando a garantir o atendimento de suas necessidades básicas. Apesar disso, houve, também, propostas de desenvolvimento para aproveitamento das potencialidades específicas e sugestões para programas de governo, como políticas sobre drogas, políticas para idosos, jovens, entre outros. Outro grupo de propostas incluiu ações do governo municipal que demandam articulações com outras esferas de governo (estadual e federal) e instituições financiadoras de políticas públicas, como saneamento básico, escolas de ensino médio e profissionalizante, metrô, infraestrutura viária, construção de hospitais, segurança pública e política sobre drogas. Esse caráter múltiplo das propostas decorreu da participação livre, sem filtro ou restrição.

\section{Conclusões}

Esta pesquisa partiu do pressuposto de que a ampliação e a qualificação da democracia não são condições inerentes a todo e qualquer processo participativo e que o formato institucional dos espaços de participação social é determinante para ampliação da cidadania. Por sua vez, ampliar a cidadania é essencial para se interferir nas políticas públicas de forma a melhorar a qualidade de vida que condiciona a promoção da saúde.

A avaliação do PPR mostrou tratar-se de uma experiência ousada pela sua amplitude, que alcançou todas as regiões de Belo Horizonte; pela exposição pública da administração e do prefeito em um processo que trazia riscos inerentes a um formato inovador de participação social, em período pré-eleitoral; pelo contexto de desencanto com a política e de baixa mobilização social, além da indefinição quanto às perspectivas de comprometimento político e de retornos concretos que poderiam advir desse processo.

Considera-se que, por se tratar de um curto ensaio de planejamento territorial participativo, são muito limitadas e comprometidas as lições. Contudo, a experiência traz inspirações técnicas e metodológicas que podem possibilitar a ampliação da cidadania, confirmadas pela percepção dos diferentes atores que dela participaram. 
Foi a postura de acolhimento das demandas populares, esforço contínuo de formação e abertura permanente à fala das lideranças que conferiu legitimidade ao PPR e à equipe executora. Dessa forma, o PPR constituiu-se num canal de diálogo que gerou uma identificação de problemas e propostas ricas, como base para um planejamento urbano mais sistêmico e inclusivo. Especialmente, propôs-se a ser um laboratório de formação para que as pessoas que dele participaram pudessem entender, de forma crítica, as dimensões técnica, jurídica, econômica e social dos processos de desenvolvimento urbano da cidade e no qual pudessem opinar sobre qualquer matéria.

Para o corpo técnico da prefeitura, foi uma possibilidade de ver que a abertura ao debate com a sociedade pode aprimorar a gestão, ao incorporar as principais demandas da população, com as quais as políticas implementadas pelo poder público nem sempre estão sintonizadas. Foi também um exercício inovador de interação entre técnicos da área de planejamento de todos os setores da prefeitura, propiciando um exercício de intersetorialidade e revelando as potencialidades de se fazer uma gestão mais integrada e sustentável.

Assim, pode-se dizer que o projeto trilhou a direção de uma experiência de planejamento territorial participativo, apesar de uma série de vácuos e limitações que podem sim representar críticas relevantes sem, no entanto, destituir a validade da experiência.

\section{Colaboradores}

As três autoras foram responsáveis pelo desenho metodológico deste artigo. Abreu MF redigiu o artigo. Melo EM e Silveira AM fizeram as correções e a revisão final. 


\section{Referências}

1. Brasil. Ministério da Saúde. Secretaria de Vigilância em Saúde. Portaria n ${ }^{\circ} 687$ MS/GM. Aprova a política de promoção e saúde. Diário Oficial da União. 30 Mar 2006.

2. Organização Mundial de Saúde. Declaração do México sobre promoção da saúde rumo a maior equidade. In: $5^{\circ}$ Conferência Internacional Sobre Promoção da Saúde; 2000 jun 5; Cidade do México. México.

3. Silva FB, Jaccoud L, Beghin N. Políticas Sociais no Brasil: Participação Social, Conselhos e Parcerias [internet]. In: Jaccoud L, organizadora. Questão Social e Políticas Sociais no Brasil Contemporâneo. Brasília, DF: IPEA; 2005. [acesso em $201828 \mathrm{dez}$ ]. Disponível em: http://www.direito.mppr.mp.br/arquivos/ File/politicassociais.pdf.

4. Pires RRC. Da sociedade para o estado: desafios da participação do Brasil. In: Marx V (organizadora). Democracia Participativa, Sociedade Civil e Território. Porto Alegre: UFRGS; CEGOV; 2014.

5. Gimenez DM, Cardoso JC. Planejamento e Desenvolvimento: Considerações à Luz de Documentos do Governo Brasileiro Entre 2003 e 2010. Brasília, DF: Ipea; 2012. (Coleção Texto para Discussão. n. 1690).

6. Santos Junior OA, Montandon DT. Síntese, Desafios e Recomendações. In: Santos Junior OA, Montandon DT, organizadores. Os planos diretores municipais pós-estatuto da cidade: balanço crítico e perspectivas. Rio de Janeiro: Letra Capital; Observatório das Cidades: IPPUR/UFRJ; 2011.

7. Minas Gerais. Prefeitura de Belo Horizonte. Cenas de um Belo Horizonte. 2. ed. Belo Horizonte: PBH; 1996.

8. Instituto Brasileiro de Geografia e Estatística. Censo 2010 [internet]. [acesso em 2015 set 09]. Disponível em: http://cidades.ibge.gov.br/xtras/perfil. php?lang $=\&$ codmun $=310620$.
9. UN-Habitat. State of the world's cities 2010/2011: Bridging the Urban Divide. Londres: Earthscan; 2010.

10. Azevedo ND, Gomes MA. Belo Horizonte: Um balanço da literatura sobre o Orçamento Participativo de Belo Horizonte: avanços e desafios. In: Azevedo S, Nabuco AL, organizadores. Democracia Participativa: a experiência de Belo Horizonte. Belo Horizonte: Leitura; 2008.

11. Abreu MF, Garcia MMF, Poznanski F. Planejamento Participativo regionalizado (PPR) - Ampliando a participação em Belo Horizonte - MG. In: Anais da $12^{\text {a }}$ Conferência do Observatório Internacional de Democracia Participativa; 2012 jun 12; Porto Alegre. Porto Alegre: Observatório da Cidade de Porto Alegre; 2012. p. 151-164.

12. Smith G. Studying democratic innovations: an analytical framework. In: Smith G. Democratic Innovations: Designing institutions for citizen participation. Cambridge: Cambridge University Press; 2010.

13. De Ferrari JM, Sanhueza A, Lauzán S, et al. Orientaciones para la práctica de la Participación Ciudadana en la Gestión Pública. In: Manual de Participación Ciudadana, Corporación Participa. Santiago de Chile: Ministério del Interior; 2008.

14. Calsing EF, organizador. Subsídios ao Planejamento Participativo - Textos Selecionados. Brasília, DF: Ministério da Educação e Cultura; 1980.

15. Demo P. Planejamento Participativo - Elementos de uma Discussão Preliminar. In: Calsing EF, organizador. Subsídios ao Planejamento Participativo - Textos Selecionados. Brasília, DF: Ministério da Educação e Cultura; 1980. p. 15-26.

16. Fedozzi L. Avaliação das práticas de construção dos Orçamentos Participativos. In: Marx V, organizadora. Democracia Participativa, Sociedade Civil e Território. Porto Alegre: CEGOV; 2014. 
17. Avritzer L, Almeida DR, Silva KJ. O Projeto Democracia Participativa PRODEP UFMG e Comitê Governamental de Gestão Participativa PBH. Repensando os mecanismos participativos de Belo Horizonte: representação, capacitação e intersetorialidade. Belo Horizonte: Relatório de pesquisa; 2010.

18. Nez H. Democracia participativa e inclusão Sócio-Política: as experiências de Bobigny (França) e Barreiro (Belo Horizonte, Brasil). Organ. Soc. 2009 jun 16(49):325-350.

19. Serafim L, Teixeira AC. Balanço e desafios do Orçamento Participativo - Gestão 2005-2008. 2006 (presumível) [internet]. [acesso em 2011 fev 2]. Disponível em: https://www.polis.org.br/download/282.pdf.

20. Cornely SA. Subsídios sobre Planejamento Participativo. In: Calsing EF, organizador. Subsídios ao Pla- nejamento Participativo - Textos Selecionados. Brasília, DF: Ministério da Educação e Cultura; 1980. p. 27-39.

21. Oliveira FJA. Participação popular em saúde: as dimensões da cultura. Cad. Saúde Pública. 2006 set; 22(11):2411-2421.

22. Valla VV. Sobre participação popular: uma questão de perspectiva. Cad. Saúde Pública. 1998; 14(supl2):7-18.

23. Serapioni M, Romaní O. Potencialidades e desafios da participação em instâncias colegiadas dos sistemas de saúde: os casos de Itália, Inglaterra e Brasil. Cad. Saúde Pública. 2016 nov; 22(11):2411-2421.

Recebido em 05/04/2018

Aprovado em 18/12/2018

Conflitos de interesses: inexistente

Suporte financeiro: não houve 